\title{
BOUNDEDNESS OF SOME SUBLINEAR OPERATORS ON WEIGHTED VARIABLE HERZ-MORREY SPACES
}

\author{
LIWEI WANG AND LISHENG SHU
}

Abstract. A new class of generalized Herz-Morrey spaces with weight and variable exponent is defined. In addition, the boundedness of some sublinear operators on such spaces is also considered. The approach is based on the Muckenhoupt theory with variable exponent and function decomposition.

Mathematics subject classification (2010): 42B20, 42B25.

Keywords and phrases: Herz-Morrey space, variable exponent, Muckenhoupt weight, sublinear operator.

\section{REFERENCES}

[1] A. Almeida AND D. DRIHem, Maximal, potential and singular type operators on Herz spaces with variable exponents, J. Math. Anal. Appl., 394 (2012), 781-795.

[2] D. CruZ-URibe And A. Fiorenza, Variable Lebesgue Spaces: Foundations and Harmonic Analysis, Applied and Numerical Harmonic Analysis, Birkhäuser, Basel, 2013.

[3] D. Cruz-Uribe, A. Fiorenza and C. Neugebauer, The maximal function on variable $L^{p}$ spaces, Ann. Acad. Sci. Fenn. Math., 28 (2003), 223-238.

[4] D. Cruz-Uribe, A. Fiorenza And C. Neugebauer, Weighted norm inequalities for the maximal operator on variable Lebesgue spaces, J. Math. Anal. Appl., 394 (2012), 744-760.

[5] Y. CHEN, S. LEVINE AND R. RAO, Variable exponent, linear growth functionals in image restoration, SIAM J. Appl. Math., 66 (2006), 1383-1406.

[6] D. Cruz-uribe, SFO, A. Fiorenza, J. Martell and C. Pérez, The boundedness of classical operators on variable $L^{p}$ spaces, Ann. Acad. Sci. Fenn. Math., 31 (2006), 239-264.

[7] L. DiENING, P. HÄstö AND S. RoudENKo, Function spaces of variable smoothness and integrability, J. Funct. Anal., 256 (2009), 1731-1768.

[8] X. FAn And D. ZhaO, On the spaces $L^{p(x)}(\Omega)$ and $W^{m, p(x)}(\Omega)$, J. Math. Anal. Appl., 263 (2001), $424-446$.

[9] P. Harjulehto, P. Hästö, Ú. V. LÊ And M. Nuortio, Overview of differential equations with non-standard growth, Nonlinear Anal., 72 (2010), 4551-4574.

[10] M. IZUKI AND T. NoI, Boundedness of fractional integrals on weighted Herz spaces with variable exponent, J. Inequal. Appl., 2016, Article ID 199 (2016).

[11] M. IZUKI AND T. NOI, An intrinsic square function on weighted Herz spaces with variable exponent, arXiv: 1606.01019.

[12] M. IZUKI, Herz and amalgam spaces with variable exponent, the Haar wavelets and greediness of the wavelet system, East J. Approx., 15 (2009), 87-109.

[13] M. IZUKI, Fractional integrals on Herz-Morrey spaces with variable exponent, Hiroshima Math. J., 40 (2010), 343-355.

[14] M. IZUKI, Boundedness of sublinear operators on Herz spaces with variable exponent and application to wavelet characterization, Anal. Math., 36 (2010), 33-50.

[15] O. KováČIK AND J. RÁKosníK, On spaces $L^{p(x)}$ and $W^{k, p(x)}$, Czech. Math. J., 41 (1991), 592-618.

[16] V. KoKILASHVILI AND S. SAMKo, Maximal and fractional operators in weighted $L^{p(x)}$ spaces, Rev. Mat. Iberoam., 20 (2004), 495-517. 
[17] S. LU AND L. XU, Boundedness of rough singular intergral operators on the homogeneous MorreyHerz spaces, Hokkaido Math. J., 34 (2005), 299-314.

[18] S. Lu, D. YANG AND G. HU, Herz type spaces and their applications, Science Press, Beijing, 2008.

[19] Y. LU AND Y. ZHU, Boundedness of multilinear Calderón-Zygmund singular operators on MorreyHerz spaces with variable exponents, Acta Math. Sin. (Engl. Ser.), 30 (2014), 1180-1194.

[20] M. RÚŽIČKA, Electrorheological fluids: modeling and mathematical theory, Springer-Verlag, Berlin, 2000.

[21] F. SORIA AND G. WeISs, A remark on singular integrals and power weights, Indiana Univ. Math. J., 43 (1994), 187-204.

[22] H. WANG, Commutators of Marcinkiewicz integrals on Herz spaces with variable exponent, Czech. Math. J., 66 (2016), 251-269.

[23] J. WU, Boundedness of some sublinear operators on Herz-Morrey spaces with variable exponent, Georgian Math. J., 21 (2014), 101-111.

[24] J. Xu, Variable Besov and Triebel-Lizorkin spaces, Ann. Acad. Sci. Fenn. Math., 33 (2008), 511-522.

[25] D. YAng, C. Zhuo And E. NAKAI, Characterizations of variable exponent Hardy spaces via Riesz transforms, Rev. Mat. Complut., 29 (2016), 245-270.

[26] D. YANG, C. ZhUO AND W. YUAN, Triebel-Lizorkin type spaces with variable exponents, Banach J. Math. Anal., 9 (2015), 146-202.

[27] D. YANG, C. ZHUO AND W. YUAN, Besov-type spaces with variable smoothness and integrability, J. Funct. Anal., 269 (2015), 1840-1898.

[28] P. Zhang AND J. WU, Commutators for the maximal function on Lebesgue spaces with variable exponent, Math. Inequal. Appl., 17 (2014), 1375-1386. 